\title{
Managing teams for instructional change: Understanding three types of diversity
}

\author{
Alice Olmstead, ${ }^{1}$ Charles Henderson, ${ }^{1}$ and Andrea Beach ${ }^{1}$ \\ ${ }^{1}$ Western Michigan University, Center for Research on Instructional Change in Postsecondary Education, Kalamazoo, MI 49008
}

\begin{abstract}
Although using teams of change agents to improve undergraduate STEM instruction is a promising strategy, little has been done to investigate how such teams can be structured and managed effectively. In particular, it is unusual for higher education researchers to critically examine the effects of diversity on team processes and outcomes. Here, we explore how three types of diversity-diversity in information, values, and status - are reflected in the literature. We argue that increased attention to the different types of diversity as well as the potential challenges associated with diversity will benefit both researchers and change leaders.
\end{abstract}

\section{INTRODUCTION}

The need to improve undergraduate STEM instruction has been widely-recognized by both education researchers and policy makers [1]. Recently, proponents of instructional change have started to invest more resources into change initiatives involving teams. These initiatives are under-studied, but may offer unique affordances relative to those that focus primarily on influencing instructors individually [2]. For instance, team-based initiatives may be more likely to result in improvements being sustained within departments [3]. Teams may also be able to tackle larger projects and produce higherquality outcomes than instructors working alone [4].

Some of the benefits of using teams to improve STEM instruction are likely linked to team diversity. We agree with the widely-held stance that STEM should become more diverse, in the sense that there should be more equal representation of people across socio-demographic groups [1]. Sociodemographic diversity (i.e., diversity in gender, race, class, etc.) might broaden a team's collective experiences and thus give them better insights into a range of student experiences.

At the same time, we should not assume that "diverse teams" will create better outcomes. Socio-demographically diverse teams might not benefit from team members' experiences. Diversity may also refer to other key team member differences [5-7]. For example, differences in team members' pedagogical knowledge, disciplinary training, and their roles within their institutions could all influence the outcomes of instructional change work [1,8-11]. Thus, it is important to clarify what "diversity" means and under what circumstances it is likely to lead to improved outcomes.

A substantial amount of research in other fields focuses on team diversity and can provide useful insights [5-7]. Individual studies about the effects of diversity on team performance often reach different conclusions: some argue that diversity tends to be an asset, while others argue that it tends be detrimental or has no effect [5]. These discrepancies can be partly attributed to variations in how diversity is defined [5, 6], and illustrate why vague definitions can be problematic. Fortunately, some research has also unpacked the meaning of diversity and explored potential links between team diversity and team outcomes. In this paper, we draw attention to such work and the insights it lends to instructional change teams.

\section{FRAMEWORK OVERVIEW}

We focus on Harrison \& Klein's [6] framework for conceptualizing diversity within organizations. This framework (summarized in Table I) presents three types of diversity. For simplicity, we refer to these types as information diversity, value diversity, and status diversity, based on Harrison \& Klein's [6] variety, separation, and disparity, respectively. We note that while it is conceptually useful to separate diversity into types, these types are often inseparable in real situations. For example, all individuals with low status on a team may hold similar information and values.

We chose this framework for several reasons. First, it highlights the multifaceted nature of diversity. Moreover, the boundaries between these three types of diversity are based on theory: each type is associated with a set of mechanistic explanations for how it is likely to influence team effectiveness. This makes the potential impacts of diversity easier to discuss. Finally, this framework illustrates how teams may encounter challenges because of the natural tendencies that individuals have in particular kinds of situations. We think that this systemic view has the potential to help team members notice and modify their interactions in productive ways.

In the rest of this paper, we summarize Harrison \& Klein's framework [6]. We integrate our description with examples from the higher education literature on instructional teams.

\section{TYPES OF DIVERSITY}

\section{A. Information diversity}

Information diversity refers to variations in the taskrelevant knowledge, skills, or expertise available to team members [6]. This could include variations in the information that team members already have, and variations in team members' social networks that influence what information they can access. Researchers who focus on this definition of diversity tend see teams as information processing units, and often draw on theories about information processing and evolution [6]. These theories suggest that having many ideas to choose from can allow teams to be resilient in the face of complex, emergent challenges, and that when multiple ideas are put forward, only the best will be selected and retained. 
TABLE I. A summary of Harrison \& Klein's [6] diversity framework and how it applies to higher education instructional teams.

\begin{tabular}{|c|c|c|c|}
\hline & Information diversity & Value diversity & Status diversity \\
\hline Definition & $\begin{array}{l}\text { Differences in team members' } \\
\text { knowledge, skills, or } \\
\text { task-relevant expertise }\end{array}$ & $\begin{array}{l}\text { Differences in team members' } \\
\text { values, attitudes, or beliefs }\end{array}$ & $\begin{array}{l}\text { Differences in the proportion of } \\
\text { socially-valued assets or } \\
\text { resources held by team members }\end{array}$ \\
\hline $\begin{array}{l}\text { Examples of relevant attributes } \\
\text { for instructional teams }\end{array}$ & $\begin{array}{l}\text { Disciplinary content knowledge, } \\
\text { knowledge of education research, } \\
\text { instructional skills, knowledge of } \\
\text { students' experiences, access to } \\
\text { outside expertise }\end{array}$ & $\begin{array}{l}\text { Disciplinary ways of thinking, } \\
\text { goals for students, attitudes } \\
\text { towards education research, } \\
\text { motivation to pursue changes, } \\
\text { personality traits }\end{array}$ & $\begin{array}{l}\text { Rank within institution, } \\
\text { socio-demographic } \\
\text { characteristics, decision-making } \\
\text { authority, social capital }\end{array}$ \\
\hline Benefits of diversity & $\begin{array}{l}\text { Team has access to more } \\
\text { information, may develop } \\
\text { higher-quality outcomes }\end{array}$ & $\begin{array}{l}\text { Team may better represent } \\
\text { stakeholders' views }\end{array}$ & $\begin{array}{l}\text { May allow team members to } \\
\text { contribute at different levels }\end{array}$ \\
\hline Drawbacks of diversity & $\begin{array}{l}\text { Requires time and energy for } \\
\text { team to process information; can } \\
\text { cause communication challenges }\end{array}$ & $\begin{array}{l}\text { Can lead to limited } \\
\text { communication, relationship } \\
\text { conflict, attrition }\end{array}$ & $\begin{array}{l}\text { Contributions of lower status } \\
\text { team members may be } \\
\text { suppressed; can lead to } \\
\text { competition or withdrawal }\end{array}$ \\
\hline Optimal level of diversity & High to moderate & Moderate to low & Low (inherent or negotiated) \\
\hline
\end{tabular}

Certain aspects of information diversity are frequently discussed in the literature about team-based instructional change in higher education. These researchers typically assume that teams benefit from having as many informational resources available to them as possible, consistent with the theories described above. Specifically, researchers often suggest that team members' knowledge of education research and disciplinary expertise enable the development of high-quality materials and instructional strategies (e.g., [8-10]). Different team members may also contribute importantly different information. For example, Redish \& Cooke [10] argue that they were able to design authentic interdisciplinary tasks for students because the physicists and biologists on their team contributed unique disciplinary knowledge. Authors also suggest that team members' social networks, such as their connections to education communities [8] or current students [11], may enable them to contribute useful information.

Team members may also be recruited based on their sociodemographic characteristics, specific life experiences (e.g., where they grew up, their career paths), or a combination of such factors. An underlying reason for these recruitment decisions may trace back to the principles of information diversity. In efforts to improve STEM instruction to better support students who belong to historically marginalized groups, leaders may assume that team members who share certain characteristics with those students can provide key insights. Sabella et al. [11] provide a well-justified example of this in describing the Learning Assistant (LA) program at Chicago State University (CSU). They argue that students at CSU can provide critical input for instructional decisions because they have rich knowledge of their peers' cultural backgrounds that is not readily accessible to faculty.

Researchers who focus on information diversity often argue that task-related conflict mediates team effectiveness: it is through conflict that the highest-quality solutions become clear [7, 14]. If team members do not or cannot effectively share the information they have, team outcomes may suffer. Team members may withhold certain information because they do not expect their team members to understand it [18]. Team members may also preferentially provide information that they already share with others as a way to foster team cohesion [15]. Thus, information diversity can enable a team to develop high-quality solutions to complex problems, but communication challenges may limit team effectiveness.

\section{B. Value diversity}

Value diversity encompasses differences in team members' values, attitudes, or beliefs [6], particularly as they pertain to the team's task. Perceived differences in values, which may be linked to socio-demographic differences, can have similar effects $[5,13]$. Theories that align with a focus on value diversity tend to explain how real and perceived differences in values, attitudes, or beliefs can divide team members, while similarities can unite them $[5,6]$. One theory predicts that people will like and want to associate with others who seem to have similar values [12]. Related theories argue that people often implicitly sort each other into "in-groups" and "outgroups" based on their knowledge and perceptions of their own and others' values. Team members may show favoritism to those who they think are part of the "in-group," while discriminating against those in the "out-group." Finally, theory suggests that a team's values may become increasingly homogeneous over time through changes in team membership. Those who share a team's dominant values may be preferentially recruited for and join it, while team members with opposing values preferentially leave. 
Consistent with these theories, researchers in higher education often claim that shared values enhance collaboration around instruction. Chasteen et al. [8] describe how physics faculty who participated in an upper level curriculum redesign at the University of Colorado-Boulder had already decided that instructional changes were needed and wanted to build on education research insights - values which clearly aligned with the values of the team leaders. These shared values strengthened the group's cohesion. Similarly, Redish $\&$ Cooke [10] explain how they initiated their collaboration because they perceived a strong similarity in their goals to incorporate authentic biology into physics courses and vice versa. This overarching shared value may have helped to facilitate their sustained partnership despite the many significant cultural differences the authors identify. Broad, shared values, such as a shared goal of helping students, may also strengthen instructional collaboration [11].

Other higher education researchers have identified how differences in values can reduce cohesion and lead to less effective instructional collaboration. For instance, although the interdisciplinary collaboration of Redish \& Cooke [10] was highly effective, Strober [16] provides several examples of how the kinds of cultural differences that Redish \& Cooke [10] identify may lead to extensive, unresolved disputes during interdisciplinary conversations. Strober [16] also claims that a lack of agreement about the purpose of interdisciplinary groups among faculty likely exacerbated these challenges.

As with information diversity, theories about value diversity support and tie together these findings. Theory predicts that individuals who share relevant values, beliefs, and attitudes will more easily socially integrate as a team [13, 17]. While a team may be able to function well with moderate value diversity, maximum diversity - in this case, when a team can be split into two factions based on team members' diametrically opposing views-is often detrimental $[6,13]$. Teams with highly diverse values may experience low social integration [13, 17], high relationship conflict [14], and high turnover [17]. All of these may decrease team effectiveness.

\section{Status diversity}

Status diversity represents differences in the proportion of socially-valued assets or resources that each team member holds. These assets can include pay, prestige, decisionmaking authority, and social capital within and outside of the team [6]. The proportion of assets each team member holds is often linked to broad patterns in society at large that assign value to certain characteristics. However, the relative status of individuals within the team is also locally constructed and can be renegotiated. A formal leader might choose to share decision-making authority with team members [5, 13]. Team members might also support each other and increase their social capital by forming coalitions [13]. Theories about status diversity attempt to explain how and why social or economic resources are unequally distributed in society, and what can happen when some people are given less than others around them [6]. In part, these theories suggest that team members who have more status tend to speak more, interrupt more, and try to direct the team's conversation more often, while those who have less tend to speak less, withdraw from team interactions, and/or defer to others' ideas [20].

The detrimental effects of status diversity as it pertains to (at least some) socio-demographic differences are wellknown and well-documented. For example, most STEM education scholars are likely aware of research findings which show that women are more likely to be interrupted during conversations than men [19]. Yet status diversity often is not explored in accounts of teams working to improve STEM instruction. Some relevant team member characteristics tend to be omitted. Others, like team members' role within their institution, might be mentioned but not explored. For example, Redish \& Cooke's work [10] included graduate students and postdoctoral researchers in addition to faculty, while Chasteen et al. [8]'s work included collaboration between a postdoctoral researcher and faculty. In this case, the authors do not describe team interactions in enough detail for us to learn how differences in rank influenced team discussions, and if team members found ways to minimize power imbalances.

Sabella et al. [11] again provide a useful counterexample by explicitly considering issues of control in faculty-LA partnerships. They characterize faculty-LA relationships as ranging from mentor-mentee partnerships to collaborative ones based on how much input the LAs have during instructional decision-making. Faculty in the collaborative partnerships enabled LAs to participate more fully, which required faculty to give up some of the control they usually hold. The authors argue that when status differences are minimized, the quality of instruction tends to be enhanced. This is particularly true when LAs are enthusiastic and sufficiently knowledgeable, such that they contribute more when invited to do so.

High status diversity within a team is typically thought to weaken its effectiveness. Lower status team members are less likely to be able to contribute substantively to the team's work $[15,20]$. This can be especially problematic when they hold unique information relative to other team members. Again, the definition of maximum diversity differs from the previous situation: here, maximum diversity implies, colloquially, that one person has everything while all others have nothing [6]. The most effective teams likely work to distribute power more equally and counteract inherent status differences.

\section{DISCUSSION}

The research captured by Harrison \& Klein's framework [6] aligns well with descriptions of instructional teams. Research outside of higher education also provides more extensive characterizations of team processes and the challenges teams may encounter because of team diversity. More empirical work to test these theories in the context of higher education would be beneficial. From a practical standpoint, we 
offer the following recommendations for change leaders:

1. Information diversity can be an asset, but only if there are sufficient supports in place to reduce possible communication challenges. Teams with high information diversity likely need supports to improve communication among team members. These supports might include sufficient time spent working together (e.g., frequent meetings, sustained collaboration), team members who are able to translate ideas across the group, and clearly-defined and challenging team tasks [7].

2. It is best to avoid creating a team that can be split into opposing factions based on real or perceived differences in values. When assembling a team, it may be useful to think about team members' values and become aware of potentially relevant differences. Researchers have suggested that teams are most likely to fracture along "faultlines," that is, imaginary lines that divide the team into subgroups based on similarities and differences in several real or perceived values [13]. If a team seems likely to fracture in a particular way, change leaders could bring in other team members who would bridge the gaps [13]. Helping team members to identify their values $[13,16]$ and/or drawing out common values across subgroups [5] could also mitigate potential problems.

3. Change leaders should pay attention to power dynamics and work to reduce localized status diversity. Status diversity can lead to unshared and unused information, and thus can weaken team effectiveness. While some aspects of local status diversity are relatively fixed, many can be renegotiated. Formal leaders and other team members can work to empower initially lower status team members by encouraging and recognizing their contributions to the team's work $[5,13,15]$, and may increase team effectiveness accordingly.
4. The more diversity there is on a team, the more important it is to actively manage team processes. Even if team leaders are able to anticipate some strengths and challenges for a particular team, it is unlikely that they will be able to fully predict what will unfold [5]. Team interactions are complex, and different aspects of diversity may become salient at different times. Thus, it is important to observe team processes and try to address emergent challenges.

\section{v. CONCLUSIONS}

In this paper we have argued that diversity is not a single construct. Researchers and practitioners can use the three types of diversity identified to provide richer accounts of team-based initiatives to improve undergraduate STEM instruction. Descriptions of instructional change often focus on how positive outcomes can emerge from the diverse knowledge and shared values of team members. While such outcomes are consistent with theory, theory also tells us that collaboration is not always smooth. If we learn more about how team processes tend to unfold in the context of instructional change work, we will likely become better able to leverage the potential benefits of diverse teams.

\section{ACKNOWLEDGMENTS}

This work is supported by NSF-DUE 1525393 . The authors thank Stephen Secules, Laura Blecha, and the CRICPE group for their feedback.
[1] Transforming Institutions: Undergraduate STEM Education for the 21st Century, edited by G. C. Weaver et al. (Purdue University Press, West Lafeyette, 2016).

[2] C. Henderson, A. Beach, \& N. Finkelstein, J. Res. Sci. Teach. 48(8), 952-984 (2011).

[3] J. C. Corbo, D. L. Reinholz, M. H. Dancy, S. Deetz, \& N. Finkelstein, Phys. Rev. Phys. Educ. Res., 12(1), 10113 (2016).

[4] J. R. Katzenbach \& D. K. Smith, Harv. Bus. Rev., 71(2), 111120 (1993).

[5] E. Mannix \& M. A. Neale, Psychol. Sci. Public Interest 6(2), 31-55 (2005).

[6] D. Harrison \& K. J. Klein, Acad. of Manag. Rev., 32(4), 11991228 (2007).

[7] R. Karlgaard \& M. S. Malone, Team genius: The new science of high-performing organizations (HarperCollins, 2015).

[8] S. V. Chasteen et al., Phys. Rev. ST Phys. Educ. Res., 11(2), 20110 (2015).

[9] J. Bouwma-Gearhart, K. H. Perry, \& J. B. Presley, J. Coll. Sci. Teach., 44(1), 40-47 (2014).

[10] E. F. Redish \& T. J. Cooke, CBE Life Sci. Educ., 12(2), 175$186(2013)$

[11] M. S. Sabella, A. G. Van Duzor, \& F. Davenport, 2016 PERC Proceedings, 288-291 (2016).
[12] D. Byrne. The attraction paradigm, (Academic Press, New York, 1971).

[13] D. C. Lau \& J. K. Murnighan. Acad. Manag. Rev., 23(2), 325340 (1998).

[14] K. A. Jehn \& E. A. Mannix, Acad. Manag. J., 44(2), 238-251 (2001).

[15] G. M. Wittenbaum \& G. Stasser, in What's social about social cognition?, edited by J. L. Nye \& A. M. Brower (SAGE Publications, Thousand Oaks, 1996).

[16] M. Strober, Interdiscplinary conversations: Challenging habits of thought (Stanford University Press, Stanford, 2011).

[17] C. A. O'Reilly III, D. F. Caldwell, \& W. P. Barnett, Adm. Sci. Q., 34(1), 21-37 (1989).

[18] J. S. Bunderson \& K. M. Sutcliffe, Acad. of Manag. J., 45(5), 875-893 (2002).

[19] D. H. Zimmerman \& C. West, in Language and sex: Difference and dominance, edited by B. Thorne \& N. Henley (Newbury House, Rowley, 1975).

[20] D. Keltner, D. H. Gruenfeld, \& C. Anderson, Psych. Rev., 110(2), 265-284 (2003). 